\title{
Politicas de ampliação da jornada escolar: em destaque as propostas de Educação em Tempo Integral no contexto do Programa Mais Educação
}

\author{
School journey enlargement policies: highlighting the proposals for full time education in the context of \\ the More Education Program
}

Politiques d'elargissement du voyage scolaire: mettant en evidence les propositions pour un enseignement à temps plein dans le cadre du Programme Plus d' Éducation

Marília Beatriz Ferreira Abdulmassih ${ }^{1}$

Universidade Federal do Piauí

Antonio Chizzotti ${ }^{2}$

Pontifícia Universidade Católica de São Paulo

RESUMO: O presente artigo, tem por objetivo analisar as políticas de ampliação da jornada escolar no contexto do Programa Mais Educação, como mola impulsionadora para a melhoria do desempenho dos estudantes da educação básica, através do maior tempo de permanência nos espaços escolares. Pode-se considerar que, a Educação em tempo integral e a ampliação do tempo de permanência dos estudantes, permite à escola enquanto espaço de reelaboração do conhecimento, incorporar em seu currículo atividades para o desenvolvimento de competências cognitivas e atitudinais necessárias a uma formação cidadã. Observa-se também, que existe uma enorme distância entre o discurso e a intenção, para que essas propostas realmente se efetivem.

Palavras-Chave: Ampliação da jornada escolar. Programa Mais Educação. Educação em Tempo Integral.

ABSTRACT: The purpose of this article is to analyse the policies for extending the school day within the context of the More education program, as a vehicle for improving the performance of students in their basic education by spending more time in school. Some consider that full time education and an increase in students time school, allows the school, as a place for knowledge re-elaboration, to incorporate activities for the development of cognitive and attitudinal skills, in its curriculum, that are necessary to form good citizens. It is also observed that there is a huge gap between discussion and intention, for these proposals to actually be realized.

Keywords: Extension of the Scholl day. More Education Program. Full time education.

RESUMÉ: Le but de cet article est d'analyser les politiques de prolongation de la journée scolaire dans le cadre du programme Plus D'education, comme moyen d'améliorer les performances des éléves dans leur education de base en passant plus de temps à école. Certains considèrent que l'éducation à temps plein et l' augimentation du temps des éléves à

\footnotetext{
${ }^{1}$ Doutora em Educação- Currículo- PUC/SP- Professora Adjunta no Departamento de Ciências Biológicas da Universidade Federal do Piauí - Campus Professora Cinobelina Elvas. Email: mariliaabdulmassih@yahoo.com.br. ORCID: https://orcid.org/0000-0002-4196-7889. Lattes: http://lattes.cnpq.br/3750899998057931.

${ }^{2}$ Doutor em Educação- Currículo- PUC- SP- Professor Associado do Programa de Pós Graduação da Pontifícia Universidade Católica de São Paulo- PUC SP- Email: -anchizzo@uol.com. ORCID: https://orcid.org/0000o002-2752-2330. Lattes: http://lattes.cnpq.br/7886576325991695.
} 
l'école permettent à l'école, en tant que lieu de réélaboration des connaissances, d'incorporer dans son programme des activités de développement des compétences cognitives et attitudinales nécessaires à la formation de bons citoens. Il est également observe qu'il existe un énorme fossé entre la discussion et l'intention, pour que ces propositions soient réellement réalisées.

Mots-clés: Prolongation de la journée scolaire. Plus de programa d'Education. Éducation à plein temps.

Recebido em: 15 de Dezembro de 2019 Aceito em: 09 de janeiro 2020

\section{INTRODUÇÃO}

Tendo em vista a intensificação dos debates acerca da educação em tempo integral e da ampliação da jornada escolar surgem propostas governamentais, na perspectiva de melhorar o desempenho dos estudantes, principalmente nas avaliações de larga escala.

Os debates atuais sobre a ampliação do tempo de permanência dos estudantes nas instituições escolares, trazem novamente em cena, os questionamentos sobre a formação integral desses estudantes e às definições controversas do que seja realmente uma Educação Integral.

As escolas são hoje chamadas a assumir funções mais amplas nas sociedades contemporâneas! É inevitável que assim seja, apesar de ser necessário reconhecer que algumas das reivindicações que têm tido a instituição escolar como alvo são, porventura excessivas e, como tal, são imprevidentes no momento em que tendem a descaracterizar a instituição escolar como uma instituição de natureza cultura (COSME e TRINDADE, 2007 p.13).

Corroborando com os autores, as escolas hoje tendem a assumir funções também de caráter assistencialista, uma vez que atendem e auxiliam sem ônus as famílias que não têm onde deixar seus filhos durante a jornada de trabalho.

Para Pacheco (2000), a socialização do sujeito é uma das finalidades da escola e servirá para prepará-lo para a sociedade, fornecendo-lhe hábitos de trabalho e habilidades intelectuais e manuais. Nesse contexto, a escola desempenha obrigatoriamente também, a função de socialização global e de educação geral.

A escola é, assim, a agência de socialização na qual as crianças experimentam pela primeira vez, um sistema institucionalizado de diferenciação com base na realização individual, o qual procura incutir a aceitação das regras de competição próprias da estrutura social e econômica. (AFONSO, 1998, p.39).

Nesse momento em que se discute a crise na e da educação escolar, onde a escola repensa suas ações e suas práticas, sua organização e suas concepções e no entendimento de 
que a escola é perpassada por diferentes realidades que pode-se observar, que o mundo escolar é muito mais plural do que se imagina.

Muito embora os discursos sobre a crise da educação escolar sejam tão antigos como a própria Escola, os fatores supostamente geradores da atual crise são hoje mais amplos e heterogêneos. Talvez mais do que em qualquer outra época, as referências à crise da educação escolar no contexto atual remetem (implícita e explicitamente) para condicionantes econômicos, sociais e político-ideológicos muito diversificados e, consequentemente, as explicações produzidas e divulgadas são hoje mais heterogêneas e contraditórias. (AFONSO. 2012a, p.15).

Uma nova fase se iniciara e dentro do contexto da análise da escola, seus problemas, seus avanços e recuos, o processo de avaliação, a questão da oferta de oportunidades iguais para todos e as políticas públicas é que surge o interesse por este estudo. As questões da melhoria da qualidade do ensino e da aprendizagem dos alunos, a partir de programas governamentais de avaliação de desempenho vêm sendo discutidas em âmbito mundial.

As funções da avaliação têm que ser, por isso, compreendidas no contexto das mudanças educacionais e das mudanças econômicas e políticas mais amplas. Aliás, a avaliação é ela própria uma atividade política como se constata, por exemplo, quando se estuda e pratica a investigação avaliativa, nomeadamente pela análise sociológica de programas educacionais e de políticas públicas. (AFONSO, 1998 p.32).

O discurso referente à qualidade da educação pública assume como base também na atualidade, os resultados das avaliações externas.

Nesta modalidade de avaliação, os resultados quantificáveis (por exemplo os que se referem ao domínio cognitivo e instrumental) tornam-se mais importantes do que os que se referem a outros domínios ou outras aprendizagens. (AFONSO,1998 p. 53).

Podemos destacar com relevância que a qualidade da educação, objeto constante de análise nas políticas educacionais nas últimas décadas, sendo mensurada somente por índices, acaba sendo simplificada, já que inúmeros aspectos e fatores relevantes para uma educação de qualidade ficam à margem de tal medição.

O conceito de qualidade que costura tais propostas tem como única alternativa a normalização dos sujeitos, culturas, processos e práticas, ou seja, exclusão da diferença, negação da alteridade, ajuste do outro às identidades fixadas pelo modelo hegemônico e segregação daqueles que não se conformam às normas. (ESTEBAN, 2010, p. 47).

A partir dos resultados obtidos nas análises dos programas de avaliação de desempenho, nas análises do fracasso e do insucesso escolar, e na busca de ofertas de 
oportunidades iguais para todos, ganham força também as políticas de ampliação de jornada escolar como fator relevante à melhoria da qualidade do ensino.

Para Pires (2012) "ganha força normativa a ideia de que uma maior permanência dos alunos num contexto escolar e enquadrados em atividades com a intencionalidade educativa conduz à melhoria dos resultados escolares".

Com a ideia de maior permanência dos alunos em contextos e espaços escolares, as temáticas de ampliação da jornada escolar, de educação integral, tempo integral, vêm ganhando espaço no debate educacional, principalmente com a implementação de várias ações do poder público e da sociedade civil e carregam novas concepções de educação, conduzindo uma ressignificação de vários aspectos do contexto escolar, sejam o papel da escola, o tempo e o espaço, a gestão, a prática pedagógica, a avaliação, o financiamento, a formação docente e até mesmo a organização curricular.

Sua vitalidade se manifesta nas políticas públicas e em projetos emanados de organizações não governamentais, movimentos sociais e mesmo instituições privadas; lembrando-se que tempo integral ou ampliação de jornada escolar não significam necessariamente Educação Integral.

Ao estabelecer a educação como processo formativo, a LDBEN 9394/96, no seu artigo $1^{\circ}$ estabelece que esse processo se desenvolve mediante a interação do educando com várias fontes de estímulo educativo, revelando a amplitude do conceito de educação, até mesmo além dos muros da escola.

Art. $1^{\circ}-\mathrm{A}$ educação abrange os processos formativos que se desenvolvem na vida familiar, na convivência humana, no trabalho, nas instituições de ensino e pesquisa, nos movimentos sociais e organizações da sociedade civil e nas manifestações culturais (CARNEIRO, 2013, p. 37).

No auge das discussões sobre a ampliação da jornada escolar, e tendo como referência o Índice de Desenvolvimento da Educação Básica- IDEB, o governo passou a destinar recursos técnicos e financeiros para os municípios cujo desempenho estivesse abaixo do esperado.

Considerando o IDEB, o Fundo Nacional de Desenvolvimento da Educação- FNDE selecionou os municípios que usufruiriam dos benefícios, mas os municípios teriam que aderir ao termo de adesão e de cooperação, que seria a condição indispensável para elaboração e implantação do Plano de Ações Articuladas (PAR).

O PAR tem uma importância significativa no contexto das políticas educacionais e sua elaboração fica a cargo de cada Secretaria Municipal de Educação por meio do comitê local, composto por representantes da sociedade e supervisores técnicos enviados pelo MEC. 
O PAR é um instrumento de planejamento da educação, por um período de quatro anos, que estabelece ações financiadas pelo Ministério da Educação-MEC; é um plano estratégico de caráter plurianual e multidimensional, que possibilita a conversão dos esforços e das ações do MEC, das Secretarias de Estado e municípios, num sistema nacional de educação.

Após realizar o diagnóstico da situação do município, os dados são enviados por meio de cadastro realizado no Sistema Integrado de Monitoramento Execução e Controle do Ministério da Educação (SIMEC), módulo PAR.

A elaboração do PAR é requisito necessário para o recebimento de assistência técnica e financeira do MEC/FNDE, de acordo com a resolução CD/FNDE n. ${ }^{\circ}$ 14, de 8 de junho de 2012. Para Cardoso (2013, p. 45), "na pratica o governo com o PAR, queria ir até os municípios para estabelecer um regime de colaboração por adesão que fosse considerado voluntario e não impositivo ao município”.

Os trabalhos de implantação do PAR contaram com um arranjo organizacional constituído por membros da Diretoria de Articulação e Apoio aos Sistemas da Educação Básica (DASI) da Secretaria de Educação Básica do MEC, do Fundo de Manutenção e Desenvolvimento da Educação Básica e de Valorização dos Profissionais da Educação (FUNDEB) e por quarenta consultores que foram designados para o trabalho de campo.

O PAR deve ser elaborado por estados, municípios e Distrito Federal, a partir da adesão do Plano de Metas Compromisso Todos pela Educação, instituído pelo Decreto 6.094 de 24 de abril de 2007 e é um programa estratégico do Plano de Desenvolvimento da Educação (PDE).

Não existe prazo para a elaboração do PAR, mas a demora na sua finalização pode retardar a assistência técnica e financeira do programa do MEC e do FNDE.

O FUNDEB destacou-se como um dos mecanismos que impulsionaram a matrícula na educação básica ao atribuir um acréscimo de $25 \%$ dos recursos às escolas que estendessem sua jornada para um período maior que sete horas.

Assim, durante o segundo mandato (2007-2010) do então presidente da república Luís Inácio Lula da Silva, instituído pela Portaria Interministerial n. ${ }^{\circ} 17 / 2007$ e pelo Decreto n. ${ }^{\circ}$ 7.083, de 27 de janeiro de 2010, que integra as ações do PDE, do PAR e do FNDE, surge o Programa Mais Educação, como uma estratégia do governo federal para induzir a ampliação da jornada escolar e a organização curricular na perspectiva de educação integral e como política de ação contra a pobreza, exclusão social e marginalidade cultural.

$\mathrm{Na}$ atualidade, o Mais Educação pode ser destacado como o mais significativo programa para a indução da educação integral. Ressaltando que governos anteriores já mantiveram propostas similares, que foram descontinuadas por não serem políticas de Estado e sim políticas de governo. 
O Programa Mais Educação prevê ações socioeducativas no contraturno das escolas, defendendo a ideia de que um maior tempo de permanência dos alunos em espaços educativos sobre a responsabilidade da escola seja a solução para a questão da melhora da qualidade do ensino.

O Plano de Desenvolvimento da Educação - PDE foi uma política de integração de todas as ações fundamentais do Ministério da Educação direcionadas à manutenção e desenvolvimento de todos os níveis de ensino, de pesquisa e de avaliação.

O MEC lançou nesse plano de ação plurianual (2008-2011), cerca de 52 ações e programas visando a luta contra a pobreza, a exclusão social e a marginalização cultural (BRASIL, 2008, p. 46).

Prioritariamente no início, o Programa visava atender às escolas situadas em capitais e determinadas regiões onde havia maior risco de vulnerabilidade social, escolas estaduais, municipais e/ou distritais que foram contempladas com o PDE/Escola e que possuam o IDEB abaixo ou igual a 4,2 nas séries/anos iniciais e/ou 3,8 nas séries/anos finais; escolas que tinham índices igual ou superior a 50\% dos estudantes no Programa Bolsa Família, escolas do Campo, Escolas que tinham unidade executora própria e escolas com matrículas igual ou superior a 40 alunos.

Hoje, o Programa Mais Educação atende também às escolas indígenas, de fronteira, nas regiões norte e nordeste do país, visando a um maior intercâmbio cultural entre elas. $\mathrm{O}$ programa possibilitou a inclusão das escolas por adesão, e as que quisessem participar poderiam realizar seus cadastros no Sistema Integrado de Monitoramento Execução e Controle do Ministério da Educação (SIMEC), para o início das atividades nos anos de 2013 e 2014, nos prazos divulgados pela Secretaria de Educação Básica -SEB.

O Programa Mais Educação conta com o apoio de quatro ministérios: Educação, Desenvolvimento Social e Combate à Fome, Esporte e Cultura, e chega às escolas com o objetivo de formular uma política nacional de educação básica em tempo integral (BRASIL, 2010).

Expressando claramente um processo de desresponsabilização do Estado, a ampliação das funções da escola e a desvalorização do profissional docente, quando se estimula o voluntariado, e a descaracterização da escola, enquanto espaço único formativo, o Mais Educação, com outras referências históricas e teóricas, traz a ideia de que: a educação pode se dar através de redes de relações ou “teias do conhecimento" chega ao Brasil, no final do século 20.

Uma de suas influências foi justamente o já citado Movimento de Cidades Educadoras. Sob a forma de programas e parcerias, geridas por organizações não governamentais, difundiram-se soluções que defendiam o papel ativo da sociedade civil em substituição ou complementação às ações governamentais. Afirmava-se buscar uma nova 
participação de cidadãos e associações, através de convênios com empresas e outros tipos de agentes financiadores de dentro ou de fora do Estado.

Também nesse período cresceu a demanda pela participação das comunidades na vida das escolas públicas e o incentivo ao trabalho voluntário, prática que, com frequência, assumiu um caráter equivocado de utilização indevida do trabalho dos pais dos alunos na conservação da escola, na preparação de merenda e outros serviços essenciais de responsabilidade do poder público (CAVALIERE, 2010, p. 59).

A Cidade Educadora foi o movimento, na década de 1990, inspirador do Programa Mais Educação, que considerava que a educação não deve ser responsabilidade da escola, mas de abrangência de territórios educativos (CAVALIERE; MAURÍCIO, 2011).

A Declaração de Barcelona reconhece a cidade como educadora da seguinte forma:

A cidade será educadora, quando reconheça, exerça e desenvolva, para além das suas funções tradicionais (economia, social, política e de prestação de serviços), uma função educadora, isto é, quando assuma uma intencionalidade e responsabilidade, cujo objetivo seja a formação, promoção e desenvolvimento de todo os seus habitantes, a começar pelas crianças e pelos jovens (DECLARAÇÃO DE BARCELONA, CARTA DAS CIDADES EDUCADORAS, 1990).

Organizada por Moll (2006), a Trilogia — Educação Integral, Gestão Intersetorial de Territórios e Rede de Saberes - representada em três manuais, vem auxiliando a operacionalização e implementação do Programa Mais Educação, visando trabalhar e contribuir para a criação de novos espaços e tempos para que aconteçam vivências culturais.

Como a educação acontece sempre, não podemos separar o tempo de aprendizagem e o tempo da não aprendizagem, a educação se dá nos três turnos, de manhã, à tarde e à noite, enfim a todo instante.

Para suprir a carência de espaços nas escolas, uma das estratégias do programa é articulá-los no entorno das escolas, mas o que se observa é que as atividades ocorrem na sala de aula, "indicando uma concepção de escola, ou denunciando a precariedade das alternativas para além do espaço escolar” (MAURÍCIO, 2013, p. 23).

Outro fator é a integração dos turnos, mas, como a ampliação da jornada não abrange em algumas escolas a totalidade dos alunos, não há como assegurar a relação entre melhora na proficiência do IDEB e a ampliação do tempo, pois a frequência nas atividades do contraturno é facultativa.

Foi um projeto concebido como instrumento gerador de um processo de participação cidadã que possibilite a criação de um consenso sobre prioridades educativas e a assunção de responsabilidades coletivas em matéria de educação. 
As experiências relatadas sobre o Mais Educação em diversas regiões do Brasil dividem as opiniões dos educadores sobre sua eficácia enquanto proposta de indução da educação integral, pois as experiências relatadas não têm sido muito exitosas, uma vez que existe ainda grande dificuldade de operacionalização do Programa.

O Programa Mais Educação aparentemente apresenta uma inovação na sua proposta, que é a Rede de Saberes, que se constitui, basicamente, na formulação de educação integral, numa perspectiva intercultural, ou seja, uma conquista no diálogo com saberes oriundos de diversas experiências, que possam dialogar, encontrar e reestruturar-se. E, nessa escuta mútua e de troca, que se pretende construir saberes diferenciados.

Acreditando que a escola não é o único lugar onde a educação acontece, a Rede de Saberes vai induzir a articulação desses saberes diferenciados, com o funcionamento regular da escola, por meio de seu PPP, preocupando-se em oferecer várias linguagens, incorporando-as à vivência dos alunos e da comunidade.

Para que isso aconteça, o Programa Mais Educação através da Rede de Saberes coloca em diálogo as ações empreendidas pelos Ministérios da Educação (MEC), da Cultura (MinC), do Esporte (ME), do Meio Ambiente (MMA), da Ciência e da Tecnologia (MCT) e também da Secretaria Nacional da Juventude, passando a contar, a partir de 2010, também com o apoio do Ministério da Defesa, na possibilidade de expansão dos territórios educativos.

Assim, na Rede de Saberes, quanto maior for a comunicação além dos muros da escola, maior será a perspectiva de uma Educação Integral, conforme estabelece o Programa Mais Educação.

A Mandala Pedagógica de Saberes, também pertencente ativo do Programa Mais Educação nasceu em uma comunidade no Rio de Janeiro em meio a uma experiência de educação integral.

Como a Mandala, em diversas culturas primitivas e modernas representa a ligação do homem com a natureza e é o símbolo da totalidade, no Programa Mais Educação, ela vai ser vista como uma "ferramenta de auxilio" (BRASIL, 2009, p. 23), na possibilidade de poder estabelecer inúmeras trocas entre saberes diferenciados.

A proposta do Mais Educação é que cada escola construa sua Mandala Pedagógica de Saberes na articulação com toda a comunidade, por meio de uma educação intercultural.

Dentro do princípio da cidade educadora, da cidade compreendida como território pleno de experiências de vida e investigador de interpretação e transformação, na Mandala, a educação é entendida como uma formação que não se realiza somente na escola, mas que vai além dos muros dela. 
A escola e o educador trabalham juntos, e não sozinhos. Entre as escolas e comunidade circulam pelo menos dois grandes grupos de saberes. De um lado estão os saberes avalizados pela sociedade através da produção acadêmica, de teses, publicação de livros etc. Conhecimentos que se estruturam através do desenvolvimento de ideias, que são sucessivamente reprocessados.

Estes costumam ser cumulativos e lineares; ou seja, construídos na direção do menor para o maior, nunca retornando a experiências passadas, se não para revê-las. Em relação direta com a vida estão os saberes que têm origem no fazer, que têm a experiência como grande fonte. Estes conhecimentos privilegiam qual o fim das coisas, respondem às necessidades humanas. Tratam-se de conhecimentos processados de forma circular, que muitas vezes retornam para avançar (BRASIL, 2009, p.27).

Assim, a educação não se realiza sozinha, ela tem que articular o conhecimento acadêmico, científico com o saber do senso comum. A Mandala nasce da troca entre a interação dos conhecimentos escolares, dos saberes comunitários, que podem ser representados por todo o conhecimento que os alunos trazem à escola e dos programas do governo. O objetivo da Mandala dentro do Programa Mais Educação é que os alunos aprendam nas relações que possam ser construídas entre esses saberes.

Dentre os Programas do Governo Federal que integram a Mandala do Mais Educação, pode-se destacar, no Ministério do Esporte, o Programa Segundo Tempo, Esporte e Lazer na Cidade. No Ministério da Cultura, o Cine Clube na escola, o Cultura Viva e as Casas do Patrimônio.

No Ministério do Desenvolvimento Social e Combate à Fome, o PETI, o Pro Jovem Adolescente, o Centro de Referência Especializado de Assistência Social- CREAS, e Centro de Referência e Assistência Social, o CRAS.

Já no Ministério da Ciência e Tecnologia, o Casa Brasil Inclusão Digital, o Centros Vocacionais tecnológicos, o Centros Museus da Ciência, Ministério do Meio Ambiente, o Sala Verde, os Municípios Educadores Sustentáveis, os Viveiros Educadores. E no Ministério da Educação, o Pró-Info, as Salas de Recursos Multifuncionais, o Educar na Diversidade, o Escola Aberta, o Escola que Protege, o Educação Inclusiva: direito à diversidade, o Educação e direitos humanos, o Com Vidas Comissão Meio Ambiente e Qualidade de vida.

Pode-se observar que a Mandala do Mais Educação tem uma grande abrangência em todo o território nacional, e acredita-se que somente uma ação integrada voltada para a formação do indivíduo poderá criar uma sociedade mais justa, humana e igualitária, com o fim da exclusão social e o combate à pobreza, da miséria e fome em nosso país e nessa 
articulação de saberes proporcionar uma formação integral, contemplando assim a Educação Integral prevista no Programa.

Para o desenvolvimento das atividades no contraturno das escolas, de acordo com o Manual Operacional do Programa, as atividades fomentadas foram organizadas em macrocampos de Acompanhamento Pedagógico (obrigatório), Inclusão Digital, Meio Ambiente, Prevenção e Promoção da Saúde, Esporte e Lazer, Educomunicação, Direitos Humanos em Educação, Educação Científica, Cultura e Artes, Educação Econômica e Cidadania.

Para cada macrocampo existe uma possibilidade de no mínimo dez atividades para serem escolhidas pelas escolas. Esses foram os macrocampos apresentados às escolas no início do programa, e somente a partir desses é que elas podiam elaborar seus planos de atendimento.

Atualmente, em decorrência também do ingresso das escolas do campo, indígenas de fronteira e do ingresso de escolas urbanas por adesão, esses macrocampos foram reformulados e surgiram outras opções de atividades.

Os macrocampos tentam se adequar à realidade de cada escola, pois cada uma é responsável pela implementação das suas atividades de acordo com suas necessidades e possibilidades.

Para execução das atividades, as escolas, elaboram seu plano de atendimento online, no SIMEC - módulo Mais Educação. Esse plano é enviado ao técnico responsável na Secretaria Municipal de Educação do município, para validação e correção. Após a tramitação escolasecretaria de educação, o plano é enviado ao MEC, para ser aprovado e a verba liberada.

A definição das atividades a serem desenvolvidas deve estar de acordo com o Projeto Político Pedagógico das escolas, envolver a participação da comunidade escolar e membros da comunidade na escolha das atividades.

Como esse processo é lento, muitas vezes prejudica o início das atividades nas escolas, e caso não dê tempo delas mesmas serem realizadas no ano letivo corrente, precisam ser reprogramadas para o ano seguinte.

De acordo com o manual operacional, as escolas não podem programar suas atividades para serem desenvolvidas nos meses de julho, dezembro e janeiro, pois esse período é considerado de férias.

Conforme o documento Passo a Passo do Programa Mais Educação (2013), há um conjunto de orientações que visam organizar as atividades do programa nas escolas participantes, atendendo o desafio de vincular aprendizagem à vida dos alunos e alunas da educação básica.

Essa organização se dá por meio dos macrocampos, entendidos como temáticas ou campos do conhecimento a serem desenvolvidas por meio de atividades diversas que as escolas têm a opção de escolher. Cada escola conforme a orientação deve escolher seis 
atividades, por ano, dentro do universo de opções que o programa oferece, sendo obrigatória pelo menos uma atividade do macrocampo Acompanhamento Pedagógico.

As atividades escolhidas em cada escola, em atendimento à realidade dos alunos participantes, devem ser realizadas no contraturno escolar ao das atividades do ensino regular e conforme orientação contida no documento Passo a Passo (2011), devem assegurar no mínimo sete horas diárias de atividades, incluídas as do ensino regular e as atividades do programa.

\section{A questão orçamentária}

Para o desenvolvimento das atividades, as escolas contam com o repasse de verbas do Programa Dinheiro Direto na Escola (PDDE). As verbas são depositadas nas contas das escolas por intermédio de suas Unidades Executoras, as UEx, e o valor repassado varia de acordo com as atividades selecionadas, o número de alunos matriculados e registrados no censo escolar do ano anterior ao do repasse, e participantes dessas atividades.

Os recursos devem ser mantidos e geridos na conta corrente específica, aberta pelo FNDE, na agência bancária indicada pelo beneficiário.

A verba antes de ser gasta deve ser aplicada no mercado financeiro até 30 dias nas aplicações financeiras de curto prazo ou operação de mercado aberto, e mais de 30 dias em caderneta de poupança.

Os rendimentos auferidos na aplicação devem ser utilizados no objeto da transferência. As escolas têm o prazo de execução dos seus recursos financeiros até 31 de dezembro do ano corrente, os saldos positivos existentes até esse período poderão ser reprogramados pelas UExs para aplicação no ano seguinte, desde que obedecido seu emprego na execução dos objetivos das ações programadas.

Os recursos que são reprogramados para o ano seguinte dão uma perda de $30 \%$ da verba total a ser recebida pela escola. Esse problema custou a ser detectado pelas escolas que reprogramavam suas atividades e seus gastos, porque as explicações no sistema e nos manuais não são claras e de fácil compreensão.

Os recursos financeiros recebidos pelas escolas deverão ser empregados na manutenção, melhoria e conservação dos espaços físicos e na aquisição de materiais necessários para a realização das atividades que contribuem para o desenvolvimento da educação integral.

Para a aquisição dos bens de custeio e capital, as escolas devem realizar ampla pesquisa de preços, preferencialmente no comércio local. É obrigatória a apresentação de, no 
mínimo, três orçamentos. As três melhores propostas deverão ser indicadas no formulário consolidado de pesquisa de preços.

As UEx não estão sujeitas à Lei 8.666 (Lei de Licitação). A aquisição e/ou contratação de serviços deverá ser efetivada no proponente que oferecer o menor preço para o item ou lote pesquisado. Não se pode esquecer do produto de melhor qualidade; quanto ao menor preço, a qualidade deve ser avaliada cautelosamente.

As prefeituras/Seduc deverão prestar às UEx a assistência técnica e financeira necessária para cumprimento das referidas obrigações, inclusive com a disponibilidade de um contador habilitado, bem como zelar para que eles não incorram em falhas que comprometam sua regularidade ante o FNDE.

No fim de cada ano letivo, as escolas devem fazer a sua prestação de contas, e nela deve conter o Plano de Atendimento geral consolidado, cópia dos cheques assinados pelos monitores e agentes educativos, recibos de ressarcimento mensal de despesas com alimentação e transporte, termo de adesão e compromisso do voluntário, os três orçamentos das empresas, no caso de compras de materiais de custeio e de capital, os termos de doação dos bens de capital (quando for o caso), demonstrativo da execução da receita e da despesa de pagamentos efetuados, conciliação e extratos bancários (conta corrente/ CDC).

Todo o dinheiro que fica na conta da escola, até ser gasto, tem que ser obrigatoriamente aplicado, a ata final, devidamente assinada por todos do conselho fiscal da escola e o relatório das atividades desenvolvidas pelos monitores.

Todos os documentos comprobatórios de despesas relativas às aquisições e contratações, tais como notas fiscais, faturas e recibos, em originais devem ser mantidos em arquivos, em arquivos na sede da escola beneficiária.

Esses documentos comprobatórios de despesas devem constar a expressão "Pagos com recursos do FNDE/PDDE/Educação Integral” (BRASIL, FNDE, 2013).

É necessário que se registre em ata todas as decisões da UEx. Os bancos devem, sem cobrança de taxas, enviar comunicação aos beneficiários dos créditos efetuados por ordem do FNDE; abrir e manter a conta corrente identificada com o Programa/Ação solicitada pelo FNDE, fornecer, um talonário de cheque no mês, até quatro extratos do mês em curso e um do mês anterior, um cartão magnético para a consulta de extrato/saldo.

- Acordo FNDE/bancos parceiros (BRASIL, FNDE, 2013).

Não poderão ser adquiridos com recursos do Mais Educação material de limpeza, transporte escolar, merenda escolar, gás, livros didáticos e de biblioteca, nos moldes fornecidos pelo FNDE, material para uso individual do aluno e material para uso de diretor professor. 
Também não poderão ser efetuados pagamentos a pessoas com ou sem vínculo empregatício, pagamento de fornecimento de água, energia elétrica, telefone, internet, etc. Inscrição, transporte, alimentação e hospedagem de participantes em cursos, seminários e congressos, etc., nem pagamentos de tributos, excetos os incidentes sobre os bens adquiridos e/ou serviços contratados.

Pelo que se observa, esse processo de prestação de contas é extremamente burocrático e demorado, exige muito trabalho, desgaste e certo conhecimento contábil. Geralmente, as escolas precisam refazer sua prestação de contas porque ela não pode ser passível de erros.

De acordo com as instruções do Programa, é necessário que se faça um mapeamento de toda a região onde está inserida a escola e a viabilidade da execução das atividades nesses espaços. E essa tarefa deve ser realizada com toda a comunidade. Segundo Moll (2011, p. 09), “a Educação Integral pressupõe que a cidade, como um todo, e uma grande sala de aula”.

A Educação Integral também compõe as ações previstas no Plano de Desenvolvimento da Educação, o qual prevê que a formação do estudante seja feita além da escola, com a participação da família e da comunidade. Essa é uma estratégia do Ministério da Educação para induzir a ampliação da jornada escolar e a organização curricular, na perspectiva da Educação Integral, que é elemento de articulação, no bairro, do arranjo educativo local, em conexão com a comunidade que se organiza em torno da escola pública, mediante ampliação da jornada escolar, ações na área da cultura, do esporte, dos direitos humanos e do desenvolvimento social.

A ideia de "educar a várias mãos" certamente não é nova. Hoje já faz parte
do senso comum a visão de que o processo de formação acontece apenas em
parte na escola, sendo complementado em outros momentos de interação
social do dia a dia, seja em casa ou em outros espaços (físicos e virtuais) da
comunidade. (CAVALIERE,2010, p. 30).

A proposta principal do Programa Mais Educação é a ocupação dos espaços públicos como direito, ou seja, a intersetorialidade. Carvalho (2006, p. 09) menciona que "[ [...] a educação ganhou sentido multissetorial, já não se invoca a escola como único espaço de aprendizagem”.

Nesses novos tempos, onde os debates sobre a Educação Integral são intensificados, fica claro que existe um conceito que pode contribuir e muito para o entendimento dessas propostas, que é a intersetorialidade.

A intersetorialidade vem contribuir como uma orientação e reformulação de políticas públicas das novas propostas de educação integral. Em classes superlotadas, professores sobrecarregados, não é possível expandir atividades educativas, sob pena de um comprometimento ainda maior da escolaridade formal. 
Tornar realidade a Educação Integral, com intersetorialidade e governança, é humanizar as políticas sociais e educacionais, colocando no centro o ser humano e, em especial as crianças, os adolescentes, os jovens e seus educadores. (MOLL, 2011, p. 28).

Nessa concepção, forma-se a Trilogia Educação Integral, Gestão Intersetorial de Território e a Rede de Saberes, propostas nas Mandalas Pedagógicas do Programa Mais Educação.

Quando se reúne a escola com as comunidades, no desenvolvimento de projetos educacionais, promove-se além da ampliação dos espaços educativos e dos tempos escolares, a permuta de saberes diferenciados.

Por isso, vai ganhando cada dia mais espaço a ideia da parceria escola/comunidade para a multiplicação dos espaços de aprendizagem e do exercício de uma educação comunitária.

Apesar de toda a verba recebida para a execução das atividades dos planos de atendimento, não é observada uma mudança significativa na educação e na rotina destas escolas, podendo concluir que a verba que chega às contas das escolas, não é fator determinante para a prática de uma educação diferenciada.

\section{Algumas considerações}

Novamente em cena estão os debates atuais sobre a ampliação do tempo de permanência dos estudantes nas instituições escolares, e às definições controvérsias do que seja realmente uma Educação Integral.

Podemos considerar que para que realmente uma proposta de Educação Integral seja efetivada nos espaços escolares, é necessário que se efetivem as políticas educacionais de ampliação da jornada escolar, não como programas de governo, mas como políticas de Estado.

A Educação em tempo integral e a ampliação do tempo de permanência dos estudantes, permite à escola enquanto espaço de reelaboração do conhecimento, incorporar em seu currículo atividades para o desenvolvimento de competências cognitivas e atitudinais necessárias a uma formação cidadã.

O discurso referente à qualidade da educação pública assume como base também na atualidade, os resultados das avaliações externas.

Caminha-se cada vez mais para uma estandartização em detrimento aos processos, é necessário que os alunos e alunas tenham grandes resultados, não se importam os meios.

Assim destaca-se que a questão da qualidade da educação, objeto constante de análise nas políticas educacionais nas últimas décadas, vem sendo mensurada somente por índices, 
acaba sendo profundamente simplificada, já que inúmeros aspectos e fatores relevantes para uma educação de qualidade acabam sendo simplificados, e ficam à margem de tais medições.

A partir dos resultados obtidos nas análises dos programas de avaliação de desempenho, nas análises do fracasso e do insucesso escolar, e na busca de ofertas de oportunidades iguais para todos, ganham força também as políticas de ampliação da jornada escolar como fator relevante à melhoria da qualidade do ensino, e à compensação do/currículo hierarquizado e fragmentado.

Observa-se que existe uma enorme distância entre o discurso e a intenção, para que essas propostas realmente se efetivem. Lembrando que termos como tempo integral ou ampliação da jornada escolar, escola de tempo integral, não significam necessariamente Educação Integral, e as ressignificações dos vários aspectos do contexto escolar, tem tido sua vitalidade manifestada nas políticas públicas e em vários projetos de organizações não governamentais, instituições privadas e movimentos sociais.

\section{Referências}

AFONSO. A. J. Políticas Educativas e Avaliação Educacional. Braga. Universidade do Minho/Centro de Estudos em Educação e Psicologia 1998.

BRASIL. Lei $n^{\circ}$ 9.394 de 20 de dezembro de 1996. Estabelece as diretrizes e bases da educação nacional. Diário Oficial da União, Brasília, DF, 23 dez. 1996. https://doi.org/10.11606/d.7.2013.tde-10092013-151829

BRASIL. Lei $\mathrm{n}^{\circ}$ 9.394, de 20 de dezembro de 1996. Estabelece as diretrizes e bases da educação nacional. Diário Oficial da União, Brasília, DF, 23 dez. 1996. Disponível em: <http://portal.mec.gov.br/seed/arquivos/pdf/tvescola/leis/lein9394.pdf>.

https://doi.org/10.11606/d.7.2013.tde-10092013-151829

BRASIL. MINISTÉRIO DA EDUCAÇÃO. Educação integral: texto referência pra o debate nacional. Brasília, 2009.

BRASIL. Educação integral/educação integrada e(m) tempo integral: concepções e práticas da educação brasileira - mapeamento das experiências de jornada escolar ampliada no Brasil. Brasília, 2009. https://doi.org/10.14393/ufu.te.2019.925

AFONSO. A. J. Políticas Educativas e Avaliação Educacional. Braga. Universidade do Minho/Centro de Estudos em Educação e Psicologia1998. p. 32

AFONSO. A. J. Avaliação Educacional: regulação e emancipação. São Paulo: Cortez, 2009, $4^{\mathrm{a}}$ edição, p. 14-15.

AFONSO. A. J. Fragmentos de Escrita Pública. Páginas da página da educação. Porto: Profedições, $1^{\text {a }}$ edição 2012a. p. 27- 43. 
CARDOSO, J. C. M. PAR- Política Sistemíca do PDE: o caso do Arquipélago do Município do Arquipélago de Marajó. TESE (Doutorado em Educação Currículo) pontifícia Universidade católica de São Paulo- PUC 2013. https://doi.org/10.5327/z1984$\underline{4840201623647}$

CARNEIRO, M. LDB; artigo a artigo, crítica e comentada. São Paulo: Vozes. 2013.

CAVALIERE, Ana Maria. Educação Integral. In: OLIVEIRA, Dalila Andrade. et al. Dicionário trabalho, profissão e condição docente. Belo Horizonte: UFMG/Faculdade de Educação, 2010, CD ROM.

CAVALIERE, Ana Maria. Tempo de escola e qualidade na educação pública. Educação \& Sociedade, Campinas (SP), n. 100, p. 1015-1035, 2007. https://doi.org/10.1590/s0101$\underline{73302007000300018}$

CAVAliere, Ana Maria; COELHO, Ligia Martha Costa. Por onde caminham os CIEPs: uma análise após 15 anos. Cadernos de Pesquisa, São Paulo, n. 119, jul. 2003. https://doi.org/10.1590/s0100-15742003000200008

COSME. A. \& TRINDADE R. Escola a Tempo Inteiro: escola pra que te quero. Porto: Profedições, Ltda- Jornal a Página da Educação. 2007. p.13.

ESTEBAN. M.T.\& AFONSO. A. J. (orgs) Olhares e Interfaces - reflexões críticas sobre a avaliação. São Paulo: Cortez. 2010, p. 47.

MAURÍCIO, L. V. Escola pública de horário integral: o que se lê, o que se vê. In: REUNIÃO ANUAL DA ANPED, 26., 2003, Poços de Caldas. Anais eletrônicos... Poços de Caldas: ANPEd, 2003.2 Disponível em: <http://www.anped.org.br/reunioes/26/trabalhos/luciavellosomauricio.rtf>. Acesso em: O2 fev. 2009. https://doi.org/10.13037/rea-e.vol1n2.4292

MINISTÉRIO DA EDUCAÇÃO/SECAD/DEIDHUC. Mais Educação passo a passo. Brasília: 2009, p. 20-21.

MINISTÉRIO DA EDUCAÇÃO /Sepespe. Programa nacional de atenção integral à criança e ao adolescente - Pronaica, concepção geral. Brasília: 1994. (Série Documentos Básicos, n. ${ }^{\circ} 2$ ).

MIRANDA, M. G. de. Sobre tempos e espaços da escola: do princípio do conhecimento ao princípio da socialidade. Educação e Sociedade. Campinas, v. 26, n. 91, p. 639-651, maio/ago.2005. Disponível em: <http://www.scielo.br/pdf/es/v26n91/a17v2691.pdf>. Acesso em: 06 fev.2009. https://doi.org/10.1590/s0101-73302005000200017

MIRANDA, M. G. de. Literatura e representações da escola pública de horário integral. Revista Brasileira de Educação. Rio de Janeiro, n. 27, p. 40-56, set./out./nov./dez. 2004. Disponível em: <http://www.scielo.br/scielo.php?script=sci_arttext\&pid=S141324782004000300004\&lng=pt\&nrm=iso\&tlng=pt>. Acesso em: 31 jan. 2009. https://doi.org/10.1590/s1413-24782004000300004

MIRANDA, M. G. de. Escritos, representações e pressupostos da escola pública de horário integral. Em Aberto. Brasília, v. 22, n. 80, p. 15-31, abr. 2009. 
MOLL, J. et al. Caminhos da educação Integral no Brasil: direito a outros tempos e espaços educativos. Porto Alegre: Penso, 2012. 504 p. https://doi.org/10.1590/s0104$\underline{40602012000300019}$

MOLL, J. et al. (Org.). Educação integral: texto referência para o debate. 2009, Brasília: Mec, Secad. p. 22.

MOLL, J. et al.. Da crise da escola e de seu re(encontro) com a vida. Jornada de Educação Popular: pelo encontro da escola com a vida. Porto Alegre: UFRGS, 2007. p.5969. https://doi.org/10.17771/pucrio.acad.8223

PACHECO. J. A. Políticas de Integração Curricular. Porto: Porto Editora, 2000.

PIRES. C. A. A "Escola a Tempo Inteiro" - Operacionalização de uma política para o 1. ciclo do Ensino Básico: Uma abordagem pela "análise das políticas públicas". Doutoramento em Educação -Administração e Política Educacional, Universidade de Lisboa, Instituto de Educação, 2012. https://doi.org/10.33167/2184-0644.cpp2015.vin1/pp.201-227 